\title{
RESEARCH
}

Open Access

\section{Diagnostic dilemma of amyotrophic lateral sclerosis (ALS): insights from the first ALS specialized clinic in Egypt}

Hebatallah R. Rashed ${ }^{1,2^{*}}$ (D) and Mohamed A. Tork ${ }^{1,2}$

\begin{abstract}
Introduction: Amyotrophic lateral sclerosis (ALS) diagnosis could be challenging in some cases and a thorough workup should be done to rule out ALS mimics. Thus, diagnosis should be made by an experienced neurologist and should be regularly reviewed.
\end{abstract}

Objectives: Review challenging cases from the ALS clinic that were misdiagnosed as ALS.

Method/patients: This is a descriptive study. We registered data of all patients coming for evaluation in the period between December 2018 and January 2020 at the international medical center (IMC) where the ALS specialized clinic is located. All patients underwent thorough clinical assessment according to the EFNS guidelines on the Clinical Management of Amyotrophic Lateral Sclerosis (MALS), and the diagnosis of ALS was made based on El Escorial revised criteria.

Results: The records of 30 patients were available for review. Twenty-four patients out of 30 patients (80\%) were diagnosed with ALS, and 6 patients (20\%) were diagnosed with other disorders (ALS mimics). In the ALS group (24 patients), there are 18 males and 6 females (male to female ratio is 3:1); mean age of onset of ALS patients is 49.2 years \pm SD 15.1 years; 18 patients (75\%) had limb onset ALS and 6 patients (25\%) had bulbar onset ALS. In the ALS mimics group (6 patients), there were 3 patients with multifocal motor neuropathy (MMN); 1 patient with celiac disease, 1 patient with mesothelioma, and 1 patient with cervical myelopathy.

Discussion: The percentage of ALS mimics in our study is higher than that reported in previous studies. This could be due to the small sample size and the deficiency of specialized ALS centers across the country. MMN was the most common ALS mimic syndrome. Factors leading to change the diagnosis from ALS to another ALS mimic disorder were the adherence to El Escorial revised criteria for the diagnosis of ALS, following EFNS guidelines for management, and looking for demyelinating features in electrophysiological studies according to the EFNS criteria.

Keywords: IMC, Amyotrophic lateral sclerosis, ALS, MMN, Multifocal motor neuropathy, Demyelination, Celiac disease, Cervical myelopathy, Mesothelioma

\footnotetext{
*Correspondence: Rashedheba83@gmail.com

${ }^{1}$ Ain Shams University Hospital, 12 Abadir St, Alzaytoun, Cairo, Egypt

${ }^{2}$ International Medical Center (IMC), Cairo, Egypt
}

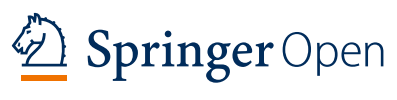

(c) The Author(s). 2020 Open Access This article is licensed under a Creative Commons Attribution 4.0 International License, which permits use, sharing, adaptation, distribution and reproduction in any medium or format, as long as you give appropriate credit to the original author(s) and the source, provide a link to the Creative Commons licence, and indicate if changes were made. The images or other third party material in this article are included in the article's Creative Commons licence, unless indicated otherwise in a credit line to the material. If material is not included in the article's Creative Commons licence and your intended use is not permitted by statutory regulation or exceeds the permitted use, you will need to obtain permission directly from the copyright holder. To view a copy of this licence, visit http://creativecommons.org/licenses/by/4.0/. 


\section{Introduction}

Amyotrophic lateral sclerosis (ALS) is a fatal and rare neurodegenerative disease which results in progressive weakness of the bulbar, limb, and respiratory muscles. Diagnosis could be challenging when the disease is limited to only one or two regions. In practice, about $5-8 \%$ of ALS patients turned out to have a different diagnosis, which could be treatable in up to $50 \%$ of the cases [1]. Thus, diagnosis should be made by an experienced neurologist and should be regularly reviewed.

The ALS specialized clinic which is located at the International Medical Center (IMC) is the first in its kind in North Africa and Arab countries. This is a multidisciplinary clinic that was established on December 15, 2019, and we aim at helping ALS patients by reaching an early diagnosis, carrying out diagnostic tests, and giving them the appropriate care to improve their quality of life. Not only patients, but we also aim at taking care of their caregivers by offering them psychological support. A team of specialized neurologists with extended experience in the ALS field is supervising the clinic and taking care of patients. Other services and specialties include respiratory therapy, physical therapy, speech therapy and rehabilitation, nutritionist, psychiatry, and psychology. The office is quiet, private, and comfortable to accommodate the patient and his caregiver. The visit duration ranges from $45-60 \mathrm{~min}$. The diagnosis is communicated by a consultant who has experience in ALS disease and with a good knowledge of the patient.

The aim of the current study is to screen the ALS patient cohort by a retrospective analysis if there were any ALS mimics that were misdiagnosed.

\section{Methods and patients}

This is a retrospective study. All patients referred to our ALS specialized clinic in the period from December 14, 2018, to January 1, 2020, were registered and underwent thorough clinical assessment and workup according to the EFNS guidelines on the Clinical Management of Amyotrophic Lateral Sclerosis (MALS) [2]. Diagnosis of ALS was made based on El Escorial revised criteria [3]. For the definition of demyelinating polyneuropathy in cases suspected to have multifocal motor neuropathy (MMN) as an ALS mimic, we used the criteria proposed by the EFNS task force [4], and all recordings met the criteria for definite/probable/possible demyelination. The study was approved by the local ethical committee of the International Medical Center (IMC), neurology department. Consent was obtained from all patients prior to participation.

\section{Results}

The records of 30 patients were available for review. After a thorough assessment and extensive workup, 24 patients out of 30 patients $(80 \%)$ were diagnosed with
ALS, and 6 patients (20\%) were diagnosed with other disorders (ALS mimics).

In the ALS group (24 patients), there are 18 males and 6 females (male to female ratio is 3:1). Mean age of onset of ALS patients is 49.2 years \pm SD 15.1 years. Eighteen patients (75\%) had limb onset ALS with mean age of onset of 47.9 years \pm 14.98 . Six patients (25\%) had bulbar onset ALS with a mean age of onset of 60.3 years \pm SD 9.05 years.

In the ALS mimics group (6 patients), there were three patients with multifocal motor neuropathy (MMN); 1 patient with celiac disease, 1 patient with mesothelioma, and 1 patient with cervical myelopathy (Table 1). All of them presented with symptoms which were referable to limbs (upper and lower extremities). MMN was the most common ALS mimic syndrome for 6 patients (50\% of cases).

\section{MMN patients}

Three patients were found to have MMN based on clinical, laboratory, and electrophysiological findings. Their symptoms started asymmetrically in upper extremities and the first sign was weakness of fingers extension. After reaching the diagnosis of MMN, IVIG was given to all the 3 patients as a loading dose $(2 \mathrm{~g} / \mathrm{kg}$ over 5 days) and monthly maintenance doses $(1 \mathrm{~g} / \mathrm{kg})$ and they are all stable and partially improved.

The first patient was a 45-year-old woman with a family history of Guillain-Barre syndrome (GBS) (mother) when she started to complain of weakness of the left hand. An outside electrophysiological study of the left median nerve (stimulated at the wrist and cubital fossa) and left ulnar nerve (stimulated at the wrist, below the elbow, and above the elbow) suggested ALS based on the findings of normal motor and sensory responses, and abnormal spontaneous activity of muscles of the left arm. She was referred to our clinic for a second opinion and management. Neurological exam revealed mild weakness of the left hand with normal reflexes all over (slightly decreased on the left side), and no other abnormality was detected on clinical exam. An extensive workup was done which revealed a positive anti-GM1 IgM antibody. Electrophysiological studies were repeated, we studied radial, median, and ulnar nerves on both sides, and stimulation was done up to Erb's point. It revealed conduction block $(\mathrm{CB})$ in the left radial nerve (between lateral brachium and axilla) and median nerve (between cubital fossa and axilla). The patient did not come for a follow-up visit, but she reported improved condition on a phone call after loading $(2 \mathrm{~g} / \mathrm{kg}$ over 5 days) and monthly maintenance doses $(1 \mathrm{~g} / \mathrm{kg})$ of IVIg.

The second patient was a 35-year-old man who started to complain of progressive weakness. It started on the left hand in December 2018 and spread gradually to involve the other hand and both legs. Initial outside EMG revealed conduction block and multifocal motor neuropathy 
Table 1 Demographics of the ALS mimic group

\begin{tabular}{lllll}
\hline Diagnosis & $\begin{array}{l}\text { Age of onset } \\
\text { (years) }\end{array}$ & $\begin{array}{l}\text { Duration } \\
\text { (months) }\end{array}$ & Clinical picture & Diagnostic measures \\
\hline MMN & 45 & 10 & Lower motor features, purely motor & $\begin{array}{l}\text { Electrophysiological studies and lab tests } \\
\text { (GM1 antibodies) }\end{array}$ \\
MMN & 35 & 15 & $\begin{array}{l}\text { Lower motor features, purely motor } \\
\text { Electrophysiological studies }\end{array}$ \\
MMN & 57 & 4 & $\begin{array}{l}\text { Lower motor features, purely motor } \\
\text { Lewer motor features, purely motor + weight loss }+\end{array}$ & Biopsy and lab tests \\
Celiac disease & 42 & 12 & $\begin{array}{l}\text { Sensory symptoms } \\
\text { Lower and upper motor features, purely motor }+\end{array}$ & Radiological tests \\
weight loss & Upper and lower motor features, purely motor & Radiological tests \\
Cervical & 63 & 3 & 12 &
\end{tabular}

diagnosis was made. He started IVIG loading ( $2 \mathrm{~g} / \mathrm{kg}$ over 5 days) and monthly maintenance dose $(0.4 \mathrm{~g} / \mathrm{kg})$, but he was not compliant. He was referred to our clinic for a second opinion as he was getting worse, and ALS diagnosis was made. Neurological exam revealed weakness of both upper and lower extremities, atrophy of small hand muscles, and diminished reflexes all over. Re-loading IVIG was given ( $2 \mathrm{~g} / \mathrm{kg}$ over 5 days) followed by monthly maintenance dose $(1 \mathrm{~g} / \mathrm{kg})$ over 2 days. After 3 months, the patient's condition was stabilized and he still receives the monthly maintenance dose.

The third patient was a 57-year-old man who started to complain of asymmetric progressive weakness of both hands since February 2019. An outside EMG supported the diagnosis of ALS. The patient was referred to our clinic for a second opinion. He had weakness on both hands, left extensor digitorum communis (EDC) weakness, occasional fasciculation of both FDI muscles, and atrophy of small hand muscles. EMG was repeated which showed demyelinating features in the form of prolonged F-wave latency $\geq 30 \%$ above the upper limit of normal value in 2 nerves and increased duration of compound motor action potentials (CMAP) in 2 nerves; there was also a drop in the amplitude between the wrist and Erb's point by $48 \%$ in the right ulnar nerve. There was abnormal spontaneous activity in the form of positive sharp waves and fibrillation potentials in both FDI and APB muscles. He received loading IVIg ( $2 \mathrm{~g} / \mathrm{kg}$ over 5 days) and regular monthly maintenance doses $(1 \mathrm{~g} / \mathrm{kg})$. The power of both hands improved, and no new weakness appeared.

\section{Celiac disease}

A 42-year-old diabetic man (his diabetes is controlled) complained of diarrhea, loss of weight, and progressive weakness since September 2019. The patient was underweight and his neurological exam revealed diffuse atrophy, symmetric weakness of both upper and lower extremities, lost reflexes and decreased pinprick and vibration sense in gloves, and stocking distribution. His electrophysiological studies showed sensori-motor axonal neuropathy. Workup revealed inflammation of the intestine and biopsy confirmed the diagnosis of celiac disease.

\section{Mesothelioma patient}

A 53-year-old man complained of right arm weakness in October 2019. He has a family history of stomach and prostate cancer (his paternal uncles). He sought medical advice and corticosteroids $20 \mathrm{mg}$ were given without making a clear diagnosis. Weakness increased, so he sought a second opinion. Electrophysiological studies were done and ALS diagnosis was made based on the findings of axonal degeneration and abnormal spontaneous activity of the right median and ulnar nerves. $\mathrm{He}$ was referred to our ALS clinic for management. Neurological exam showed atrophy of small hand muscles, asymmetric weakness of both upper extremities, occasional fasciculations of the right tricep muscles, abnormal tandem gait, and slow rapid movements of both feet. Reflexes of the right upper extremity and bilateral lower extremities are brisk, and planter reflexes were equivocal. The patient denied sphincteric involvement. An extensive workup was done including MRI cervical spine which revealed a right lung apex poorly defined soft tissue mass lesion infiltrating the right transverse process and bodies of $\mathrm{C} 7, \mathrm{D} 1$, and $\mathrm{D} 2$ vertebra, encroaching on the C6-7, C7-D1, D1-2 right neural exit foramina with possible infiltration of right 1st rib. CT chest, abdomen, and pelvis revealed circumferential right pleural thickening with pleural plaques and right lung masses suggestive for mesothelioma. Biopsy was done, and diagnosis of mesothelioma was confirmed.

\section{Cervical myelopathy}

A 67-year-old man complained of progressive stiffness of both legs and weakness of both arms since 2018. He was diagnosed with ALS and was referred to our clinic for a second opinion. He had mixed upper and lower motor features, asymmetric weakness and atrophy of the small muscle on both hands, abnormal gait, brisk reflexes, and fasciculations in the biceps and triceps. $\mathrm{He}$ 
reported occasional dribbling of urine. EMG was done which revealed multiple root affection at multiple cervical and lumbar levels. MRI cervical spine showed cervical myelopathy and multiple cervical and lumbar disc protrusion. Surgical decompression was scheduled. Reevaluation will be scheduled after the surgery.

\section{Discussion}

Currently, there is no large epidemiologic study about ALS in Egypt, and we do not have available studies about the incidence or prevalence of ALS in the country [5]. In the current study, we reviewed data of 30 patients referred to our ALS specialized clinic in the period between December 14, 2018, and January 1, 2020.

After ruling out ALS mimics, ALS diagnosis was coined to 24 patients only (80\%). Male to female ration in the ALS group is 3:1 which is in agreement with an African study [6]; however, it is higher than what is reported in some European studies [7, 8]. Mean age of onset of ALS patients is 49.2 years \pm SD 15.1 years which is not far from what was reported in previous studies [5, 7, 9-11]. Of the ALS group, the majority of ALS patients (75\%) had limb onset ALS, which is in agreement with previous studies from Egypt and different countries across the world $[5,7,9,10,12]$.

Six patients $(20 \%)$ were confirmed to have other disorders (ALS mimic disorders); the percentage of ALS mimics in our study is higher than that reported in previous studies [1]. This could be due to the small sample size and the deficiency of specialized ALS centers across the country. Out of the 6 patients, 3 patients were having $\mathrm{MMN}$, and the other 3 patients were having celiac, mesothelioma, and cervical myelopathy.

MMN was the most common ALS mimic syndrome in accordance with the study of [1]. Confusion of MMN with ALS is not uncommon in clinical practice and misdiagnosis is common [13]. MMN is a rare immunemediated neuropathy that is treatable with immunomodulatory therapy early in the course of the disease before the occurrence of axonal degeneration. Positive antiganglioside GM1 IgM antibodies and demyelinating features in electrodiagnostic studies of conduction block are useful diagnostic criteria [13].

One patient was found to have celiac disease and peripheral neuropathy which is one of the most common neurologic manifestations of celiac disease [14]. Cervical myelopathy is another important differential diagnosis of ALS [15]. Diagnosing cervical spondylosis and myelopathy in the early stage of the disease is important because it has good prognosis; however, it could be difficult [16]. Mesothelioma can cause neurological symptoms if it infiltrates adjacent structures as vertebral bodies, spinal root exits, or brachial plexus $[17,18]$.
Differentiation of these disorders might be quite challenging early in the course of the disease. Factors leading to change the diagnosis from ALS to another ALS mimic disorder were the adherence to El Escorial revised criteria for the diagnosis of ALS, following EFNS guidelines for management, and looking for demyelinating features in electrophysiological studies according to the EFNS criteria.

There are some limitations of the study that should be avoided in future studies; one of the limitations is the small sample size, which is attributed to the short period of recruitment of patients. Larger sample is needed to give better idea about epidemiology of the disease in Egypt and ALS mimic disorders. Another limitation is the non-compliance of patients with follow-up visits, which is attributed mainly to their disability.

\section{Conclusion}

Differentiation between ALS and its mimics is important in the early stages because some ALS-mimicking disorders have a better prognosis and are curable. Of the ALSmimicking disorders, $\mathrm{MMN}$ is the most common diagnosis mistaken for ALS. Other mimicking disorders are cervical myelopathy, mesothelioma, and celiac disease. Therefore, diagnosing ALS should not be made unless other disorders are ruled out by clinical, radiological, laboratory, and electrophysiological tests.

\section{Acknowledgements}

Not applicable

Conflict of interests

None (the authors declare that they have no competing interests).

Authors' contributions

HRR analyzed the data and wrote the manuscript. The authors read and approved the final manuscript.

Funding

Not applicable (we did not receive funds for this project).

\section{Ethics approval and consent to participate}

This manuscript was approved by the local Ethical Committee of neurology department, International Medical Center (IMC) on 11 June 2019. All patients signed consents by themselves to use their tests in research purposes. We confirm that we have read the Journal's position on issues involved in ethical publication and affirm that this report is consistent with those guidelines.

\section{Consent for publication}

All patients signed consents by themselves for publishing their cases. The datasets generated during and/or analyzed during the current study are available from the corresponding author on reasonable request.

Received: 25 March 2020 Accepted: 22 June 2020

Published online: 06 July 2020

\section{References}

1. Traynor BJ, Codd MB, Corr B, Forde C, Frost E, Hardiman O. Amyotrophic lateral sclerosis mimic syndromes. Arch Neurol. 2000;57:109-13.

2. The EFNS Task force on diagnosis and management of amyotrophic lateral sclerosis. EFNS guidelines on the Clinical Management of Amyotrophic 
Lateral Sclerosis (MALS) - revised report of an EFNS task force. European Journal of Neurology. 2012;19:360-75.

3. Brooks BR, Miller RG, Swash M, Munsat TL. El Escorial revisited: revised criteria for the diagnosis of amyotrophic lateral sclerosis. Amyotroph Lateral Scler Other Motor Neuron Disord. 2000;1:293-9.

4. EFNS task force/ CME article. European Federation of Neurological Societies/ Peripheral Nerve Society Guideline on management of chronic inflammatory demyelinating polyradiculoneuropathy: report of a joint task force of the European Federation of Neurological Societies and the Peripheral Nerve Society — First Revision. European Journal of Neurology 2010; 17: 356-363.

5. Hebatallah R. Rashed \& Mohamed A. Tork: Diagnostic delay among ALS patients: Egyptian study, amyotrophic lateral sclerosis and frontotemporal degeneration 2020;0:1-4.

6. Luna J, Diagana M, Ait Aissa L, Tazir M, Ali Pacha L, Kacim I, et al. Clinical features and prognosis of amyotrophic lateral sclerosis in Africa: the TROPALS study. J Neurol, Neurosurg, Psychiatry. 2019;90:20-9.

7. Palese F, Sartori A, Verriello L, Ros S. Epidemiology of amyotrophic lateral sclerosis in Friuli-Venezia Giulia, North-Eastern Italy, 2002-2014: a retrospective population-based study. Amyotroph Lateral Scler Frontotemporal Degener. 2019;20:90-9.

8. Benjaminsen E, Alstadhaug KB, Gulsvik M, Baloch FK, Odeh F. Amyotrophic lateral sclerosis in Nordland County, Norway, 2000-2015: prevalence, incidence, and clinical features. Amyotroph Lateral Scler Frontotemporal Degener. 2018;19:522-7.

9. Zhou S, Zhou Y, Qian S, Chang W, Wang L, Fan D. Amyotrophic lateral sclerosis in Beijing: epidemiologic features and prognosis from 2010 to 2015. Brain Behav. 2018;8:e01131.

10. Turgut N, Birgili O, Varol SaraCoglu G, Kat S, Balci K, Guldiken B, et al. An epidemiologic investigation of amyotrophic lateral sclerosis in Thrace, Turkey, 2006-2010. Amyotroph Lateral Scler Frontotemporal Degener. 2019; 20:100-6.

11. Ryan M, Zaldivar Vaillant T, McLaughlin RL, Doherty MA, Rooney J, Heverin $M$, et al. Comparison of the clinical and genetic features of amyotrophic lateral sclerosis across Cuban, Uruguayan and Irish clinic-based populations. J Neurol, Neurosurg, Psychiatry. 2019;90:659-65.

12. Longinetti E, Wallin A, Samuelsson K, Press R, Zachau A, Ronnevi L, et al. The Swedish motor neuron disease quality registry. Amyotroph Lateral Scler Frontotemporal Degener 2018; 19:528-537. A population-based study using data from a national MND registry that highlights the need of setting up national registries to identify and care for ALS patients.

13. Lawson V. and M Robbins NM. Motor neuropathy as amyotrophic lateral sclerosis - a case series. US Neurology. 2018;14(2):102-7.

14. Chin RL, Latov N. Peripheral neuropathy and celiac disease. Curr Treat Options Neurol. 2005;7(1):43-8.

15. Onder H, Yildiza FG. Cervical spondylotic myelopathy mimicking amyotrophic lateral sclerosis. J Neurol Res. 2016;6(4):89-90.

16. Truffert A, Rosler KM, Magistris MR. Amyotrophic lateral sclerosis versus cervical spondylotic myelopathy: a study using transcranial magnetic stimulation with recordings from the trapezius and limb muscles. Clin Neurophysiol. 2000;111(6):1031-8.

17. Baas P, Fennell D, Kerr KM, Van Schil PE, Haas RL, Peters S. Malignant pleural mesothelioma. ESMO Clinical Practice Guidelines for diagnosis, treatment and follow-up. Ann Oncol. 2015;26:v31-9.

18. Bibby AC, Tsim S, Kanellakis N, Ball H, Talbot DC, Blyth KG, et al. Malignant pleural mesothelioma: an update on investigation, diagnosis and treatment. Eur Respir Rev. 2016;25:472-86.

\section{Publisher's Note}

Springer Nature remains neutral with regard to jurisdictional claims in published maps and institutional affiliations.

\section{Submit your manuscript to a SpringerOpen ${ }^{\circ}$ journal and benefit from:}

- Convenient online submission

- Rigorous peer review

- Open access: articles freely available online

High visibility within the field

- Retaining the copyright to your article

Submit your next manuscript at $\boldsymbol{\nabla}$ springeropen.com 